\title{
Alpha-Fetoprotein (AFP): Solved and Unsolved Problems
}

\author{
G.I. Abelev ${ }^{* \mathcal{Y}}$,Ph.D., and $\underline{\text { N.L. Lazarevich }} \underline{\underline{Y}}$
}

* To whom correspondence should be addressed: Ý Laboratory of Immunochemistry, N.N.Blokhin Cancer Research Center, Russian Academy of Medical Sciences, 115478 Moscow, Russia

\section{HISTORICAL OVERVIEW}

The protein that would later be called alpha-fetoprotein (AFP) was first identified in human fetal sera by Bergstrand and Czar in 1956 on paper electrophoregrams (1). Several confirmations of this finding were made, but the potential role of the protein remained entirely unknown. In 1960, the present authors found an antigen in mouse hepatoma cells that was absent from the liver, blood, and other tissues of normal adult mice. However, the relationship of this antigen to a feto-specific serum protein was only established, unexpectedly, during the course of other study on antigenic maturation of mouse liver in ontogenesis.

The "specific hepatoma antigen" was found in tremendous amounts first in embryonal liver extract, then in embryonal serum, and finally in the blood sera of hepatoma-bearing mice. Very soon, it became clear that mouse hepatomas produce and secrete into the blood an embryo-specific serum protein. It was shown in the same work that a short-term wave-like appearance of the protein takes place at liver regeneration. The authors presented these findings at the VIIIth World Cancer Congress in July 1962 in Moscow $(2,3)$. The next year, Tatarinov demonstrated embryo-specific alpha-globulin in the serum of patients with hepatocellular carcinoma (HCC) (4). A few years later, it became clear that AFP is a valuable marker in the differential diagnosis of HCC. An important contribution to this problem was made by extensive studies in West Africa (5) and various other African regions (6). Moreover, it was found during clinical studies that AFP is also associated with teratoblastoma of the testis and ovary germ cell tumors (GCT) $(7,8)$.

The next few years brought very broad confirmation and extension of the first clinical observations, with early demonstration of the value of the AFP test in monitoring surgery and chemotherapy, primarily in GCT (8). Very active parallel investigations were carried out on rat and human AFP by Uriel et al. in France. Several highly sensitive methods for AFP detection were elaborated in the early 1970's (9), but the most practical, both in experimental systems and in clinics, was found to be radioimmunoassay (RIA), first introduced by Ruoslahti and Seppala. This assay permitted the detection of AFP from its background level to its maximal values in different pathologies (10). Later, RIA was supplanted by enzyme-linked immunoenzyme assay (ELISA), which is identical to RIA in specificity and sensitivity but more stable and ecologically acceptable. AFP ELISA kits produced by a number of companies are routinely used at present in clinical work throughout the world.

A separate and very important branch of AFP application originated from the work of Brock and Sutcliff in 
1972 (11), who demonstrated a highly elevated level of AFP in amniotic fluid in the context of fetal neural tube defects. It was later shown that the serum level of AFP in fetal malformations is also significantly increased; hence, the prenatal diagnosis of inborn neural tube defects, or more correctly, formation of highrisk groups for such defects, became possible on a serological basis (12). More recently, a serological approach has been demonstrated to be valid for prenatal diagnosis of Down syndrome (13).

\section{BIOLOGY OF AFP}

\section{Ontogeny}

Alpha-Fetoprotein (AFP) is an embryo-specific serum alpha-globulin protein that is a major component of early embryonal serum in mammals. In fact, the amount of AFP in embryonal serum is higher than the initial level of serum albumin (SA), a predominant protein of late fetal and adult sera. The synthesis of AFP is initiated with embryonal hemopoiesis in the yolk sac, particularly in the yolk sac visceral endoderm (YSVE). The YSVE is the site of synthesis of all serum proteins in early embryonic development: SA, alpha-1-antitrypsin, transferrin, and early AFP. Later, when embryonal hemopoiesis is replaced by fetal hematopoiesis, in which the liver becomes the main site of blood formation, the synthesis of AFP and the other serum proteins is transferred to the liver. Trace synthesis of AFP is noted also in the fetal gut, as the YSVE, fetal gut, and liver are closely related developmentally $(5,9,14-16)$.

It is well known that AFP is an obligatory component of embryonal and fetal hemopoiesis but little if anything is known regarding the nature of the association--whether it is functional, includes common regulatory links, or is only coincidental.

The level of AFP in the sera of newborn mice and rat sis very high (above $2 \mathrm{mg} / \mathrm{ml}$ ) due to the persistence of liver hematopoiesis, but is much lower in newborn humans $(\sim 0.1 \mathrm{mg} / \mathrm{ml})$. It drops very sharply in mice and rats (thousands-fold during the first month postnatally), and more slowly in humans over three to four months, at which time it reaches the background level of AFP that normally persists at approximately 200 $\mathrm{ng} / \mathrm{ml}$ in mice, $50 \mathrm{ng} / \mathrm{ml}$ in rats, and 5-10 ng/ml in humans. A wave-like short-term increase of serum AFP level takes place when liver injury is followed by regeneration, e.g. after hepatotoxin administration in mice and rats or acute viral hepatitis in man. Injury and necrosis formation are the necessary conditions for AFP resumption, as even massive hepatectomy followed by regeneration is much less effective in this respect $(5,15,17)$.

\section{Structure and Function}

The structure of AFP has been relatively well- characterized. It is a glycoprotein with a small (approximately $4 \%$ ) carbohydrate moiety represented by one oligosaccharide residue. The protein moiety has been completely determined, consisting of one polypeptide chain of 590 amino acids arranged in three welldefined domains, with a total molecular weight of approximately 69000 (18).

AFP is present in all mammals with a significant degree of homology but definitive immunological crossreactions between species occur, for example, among AFP in human, monkey, pig, dog, cat, and calf. Early studies of a protein similar to AFP found in birds, reptiles, amphibians, and likely in sharks, (19) are underway.

AFP is very similar in its structure and physicochemical properties to SA: the molecules have one polypeptide chain of similar length and a very high degree of homology (up to $70 \%$ in certain regions of the molecule), and consisting of three very similar domains. In addition, they possess almost identical molecular weights, isoelectric points, and barely distinguishable electrophoretic mobilities. However, SA differs from 
AFP in that it does not contain a carbohydrate moiety, and native AFP and SA do not give immunological cross-reactions, which have been obtained only in denatured molecules $(18,20)$.

A rich collection of monoclonal antibodies (MoAbs) to AFP have been obtained in different laboratories (21). A recent AFP workshop included $30 \mathrm{MoAbs}$ but, to date, only one has been determined to be directed to the carbohydrate moiety (22). MoAbs to AFP cluster on at least 7 epitopes, such that some mutual interference of binding occurs(21). The projection of the epitope map onto the physical structure of AFP has not yet been achieved, but is an important task that may lead to the development of specific reagents capable of interacting with discrete regions of the molecule that confer distinct functions of AFP.

A significant feature of AFP is its well-expressed microheterogeneity, characterized by seven subcomponents revealed by isoelectric focusing (18,23-25). Microheterogeneity of AFP is due to oligosaccharide structure, charge difference, and small distinctions in the N-terminal part of the polypeptide chain (18). Variants in the structure of the carbohydrate moiety are of primary interest, and are determined by differences in the glycosylation processes in various tissues. Thus, AFP synthesized in YSVE (and corresponding tumors) is different in carbohydrate structure from those produced in the fetal liver and in HCC. AFP of HCC origin can be distinguished from AFP produced by benign lesions in the liver $(24,25)$. The generally-accepted method of investigation of carbohydrate differences in AFP is lectin affinity chromatography and lectin affinity lectrophoresis using concanavalin A and Lens culinaris lectin. Variations in N-terminal amino acids have also been of interest, and may be due to genetic polymorphisms of the AFP gene or to posttranslational processing of its polypeptide chain.

Quite recently, it has been found that certain MoAbs might be used for separation of AFP subfractions in their native state (26). According to preliminary data, denaturation-renaturation procedures have extinguished the epitope differences among separated subfractions of AFP. If confirmed by present and future studies, this data would demonstrate the existence of Conformational AFP variants.

AFP function is one of the most intricate areas of AFP research. At present, the molecule's functions are highly speculative; yet, they are based on two firmly established observations. First is the very high affinity of AFP for polyunsaturated fatty acid (PUFA), a property unique to AFP in comparison to other serum proteins, including SA (27). Secondly, AFP has demonstrated the ability to be internalized by certain embryonal and actively-proliferating tissues (28). These findings suggested, quite plausibly, that AFP absorbs PUFA from the maternal circulation in the placenta and transports it into embryonal tissues, which are unable to produce endogenous PUFA (29). Yet, substantiation of this theory requires the characterization of the AFP receptor. At present, its existence is clear, but numerous important issues of specificity remain unknown including: whether the receptor can distinguish AFP from SA or other serum proteins; whether it is directed to the carbohydrate moiety of AFP or to its polypeptide chain; whether it is selective for subvariants of AFP; which epitope of AFP it specifically binds; whether it recognizes "naked" AFP or only AFP loaded with PUFA or other ligands; and how it is distributed between embryonal and rapidly proliferating adult tissues such as the intestine and bone marrow. To answer these questions, the isolation of the AFP receptor for extensive biochemical study, the development of MoAbs specific for the AFP receptor, and the determination of tissue distribution and intracellular fate of the AFP receptor must all be achieved. Such studies are currently in progress, and despite some contradictions and discontinuity, far-reaching conclusions are beginning to be made (30). Further research toward characterization of the AFP receptor is crucial to the understanding of AFP function, as well as to the prospective use of AFP as a specific transporter of antitumor drugs into tumor tissue (31).

The demonstration in mice and rats that AFP has a high specificity for estrogens (32) has led to the hypothesis that AFP protects embryonal tissues from maternal estrogens $(18,20)$ and may modify estrogen action on target tissues $(33,34)$. Future work may adequately account for the weak estrogen binding of human AFP. 
In other studies, AFP has been found to have immunosuppressive activity. Demonstration of both strong immunomodulatory and total absence of any suppression, depending on AFP origin, mode of purification, and subvariant composition, has led to the supposition that the immunosuppressive effect of AFP is not due to AFP alone, but to some biologically active ligand, such as PUFA, when bound to a certain AFP subfraction $(18,35)$. It has also been demonstrated that only one subfraction in AFP preparations is active in immunosuppression (36), and that AFP prevents expression of the MHC-II class molecule on macrophages (37). AFP induced MHC-II supression may inhibit antigen presentation by macrophages and likely hinders immunological maturation of the fetus. Curiously, interest in the immunosuppressive role of AFP has greatly waned in recent years.

\section{Regulation of AFP Expression at the Cellular Level}

The developmental regulation of AFP synthesis and the reasons for its reappearance in malignancy are among the most avid areas of AFP research.

The first site of AFP synthesis is the earliest-differentiated embryonic structure, the YSVE. This was shown by immunohistochemical methods and by direct demonstration of AFP synthesis in tissue culture $(38,39)$. It is very important to note that even in this tissue AFP synthesis is not constitutive but regulated by intercellular interactions (40).

AFP is detected from the very onset of liver formation, produced by all hepatocytes in the liver bud, and continues to be expressed in mice and rats up to delivery and in human fetuses up to the second half of pregnancy. The decline of AFP production coincides with formation of the definitive liver plates, which are seen well in postnatal mice and rats. This decline begins in the portal area and moves in a gradient-like manner to the central veins. The bright ring of AFP-positive cells persists around the central veins up to the complete cessation of its synthesis. It should be emphasized that hepatocyte proliferation per se is not responsible for AFP synthesis, as AFP synthesis may be resumed in non-proliferating liver cells, as well as remain dormant in proliferating tissue $(41,42)$. Interestingly, the cells responsible for AFP background production in adults have not, to date, been identified. Cholangiocytes are negative for AFP from their first appearance to their formation of well-defined ducts.

The inhibition of AFP synthesis appears reversible in all or at least most hepatocytes. This was shown in experiments with AFP induction after chemical liver injury by $\mathrm{CCl}_{4}$ and other hepatotoxins. Under these conditions AFP reappeared in a one-cell layer surrounding the necrotic area, independent of size and localization of necrosis. Any hepatocyte located in this region resumed AFP synthesis (42).

Immunohistochemical studies of such cells using electron microscopy revealed mature hepatocytes, with AFP localization in the rough endoplasmic reticulum (43). Furthermore, dissociation of adult mouse liver cells in tissue culture after collagenase perfusion has been shown to cause marked AFP synthesis in the overwhelming majority of hepatocytes (41). AFP synthesis in these cells could be completely inhibited in mixed culture with the so-called non-parenchymal epithelial liver cells. The latter formed a dense monolayer that produced extracellular matrix, inducing hepatocyte association in islands consisting of highlydifferentiated liver cells exhibiting no AFP production (44). These experiments clearly demonstrated that AFP synthesis in mature hepatocytes is reversibly repressed under the influence of intercellular interactions. The nature of this crucial interaction and the pathway from intercellular contact to specific gene activation currently await further study.

\section{AFP Regulation at the Genetic Level}

The AFP gene has been cloned and sequenced together with its regulatory region. The AFP gene belongs to the albumin gene family, together with the SA, alpha-albumin, and vitamin D-binding protein genes, and is located in humans in the same region of chromosome 4 as these related genes $(45,46)$. The SA, AFP, and 
alpha-albumin genes are arranged tandemly and possess a high level of sequence homology (46). The coding sequence of the AFP gene consists of 15 exons segregated by 14 introns, and is highly conserved among species (47).

The $7 \mathrm{~kb} \mathrm{5'}$ regulatory region of the rat and mouse AFP gene consists of a promoter approximately $200 \mathrm{bp}$ in length, three independent distal enhancers, and a silencer that is located at the 5 ' end of the promoter, and has been found necessary for AFP gene repression in adult liver (48-51). The regulatory elements of the AFP gene are responsible for its tissue-specific expression. Furthermore, individual distal enhancers determine the position-dependent expression of the AFP gene in liver lobules (52). Each enhancer is capable of activating promoters of both AFP and SA. These intergenic enhancers likely play a key role in the coordinated regulation of these genes during development (53).

While the structure of the AFP gene and its regulatory region has been firmly established, transcription factors involved in its regulation are currently under active investigation. Several factors that interact with the promoter and distal enhancers have been identified. Among them are NF1, AP1, the glucocorticoid hormonereceptor complex (GR), and the liver-specific hepatic nuclear factors, the latter of which include members of the C/EBP, HNF1 and HNF3 families (53). The recently discovered transcription factors PCF and FTF are strongly associated with AFP gene expression in different tissues and hepatoma cell lines, and although FTF has also been detected in adult liver, there is a strong possibility that both factors are AFP-specific $(53,54)$. The hepatic nuclear factors belong to the category of "master genes," and regulate the expression of an entire cluster of liver-specific genes, including SA. The particular interactions of these transcription factors in the various tissues of the gastrointestinal tract result in the tissue-specific patterns observed for AFP gene expression (55).

All the above-mentioned transcription factors interact with AFP regulatory elements primarily as transcriptional activators, but AP1, NF1, and GR may also act as transcriptional inhibitors, depending on their concentration or the presence of other transcription factors. The majority of the identified factors bind with the promoter element, with potentially overlapping binding sites for which different factors may compete. An additional layer of regulation in AFP gene expression is provided by homo- and heterodimerization of transcription factors, giving the complexes different trans-activation properties.

Whereas significant progress has been made in the study of AFP gene upregulation, the mechanism of downregulation of the AFP gene in development is not yet clear. The presence of inhibitory transcriptional regulators shutting off the AFP gene has been clearly demonstrated. One candidate is GR, which interacts with a GR-binding element in the AFP promoter and inhibits its expression in early postnatal life (49). However, in other systems, glucocorticoids act as activators of AFP expression, and the GR mechanism is not a general mechanism of AFP gene suppression. Nevertheless, deletion of the silencer region from AFP transgene constructs has been shown to lead to the maintenance of AFP reporter gene expression in the liver and intestine of adult transgenic mice (51). Hence, it appears that the adult liver maintains production of transcription factors necessary for AFP gene expression, the latter of which is normally inhibited by one or more factors interacting with the silencer.

Based on earlier findings that a raf genetic locus capable of modulating the AFP background level in adult mouse liver has been identified (56) and that $r a f$ may act at the posttranscriptional level (57), a recent model has proposed that the raf protein interacts with the AFP promoter or silencer elements to inhibit transcription postnatally (58). The identification of the raf gene product may thus add greatly to the current understanding of postnatal AFP gene regulation. In addition, much work toward the identification of additional inhibitory transcription factors remains (59). 
AFP is a specific marker of embryonal carcinoma (EC), as only this type of tumor as distinct from seminoma, disgerminoma and stromal cell tumors, is able to generate YSVE elements. Such elements are responsible for AFP production in tumors just as in the normal embryo $(9,60)$. The presence and amount of YSVE elements in the particular tumor determine the presence and level of serum AFP in the corresponding patient, emphasizing the centrality of the histological structure of the tumor rather than its anatomic localization. Tumors of testicular or ovarian localization and retroperitoneal tumors of EC nature can be equally well diagnosed by AFP levels.

The occurrence of AFP production in EC is very high (up to 80\%) (15). In addition, Teilum's tumors--yolk sac tumors arising from YSVE elements that have separated from a pre-existing tumor (61)--are always AFPpositive, with a high serum level of the marker. It should be noted that GCTs also produces chorionic gonadotrophin (CGT), but by histological elements other than YSVE--namely by cells of syncitiotrophoblast nature. Both markers are used together in differential diagnosis and monitoring of germ cell tumors (62), which respond well to chemotherapy and are curable in a high percentage of cases. In the future, should the establishment of high-risk groups for development of GCT be achieved, earlier diagnosis of GCT in the prenatal stage may become a reality.

\section{AFP in Hepatoblastoma (Hb) and HCC}

Pediatric $\mathrm{Hb}$ is a distinct entity from HCC, consisting of hepatoblast-like cells similar to embryonal liver parenchymal cells, and secreting large amounts of AFP in up to $90 \%$ of tumors (15).

With HCC, despite a relatively high incidence of increased AFP levels of up to 70-80\% over the background level, the correlation of increased AFP levels of pathological grade is less clear. The overall tendency is for resumed AFP production in poorly differentiated tumors and for its absence in highly differentiated, minimal hepatomas $(14,17)$. However, many exceptions exist, including: loss of AFP production by strongly AFPpositive tumor strains even without any visible changes in the degree of differentiation; large heterogeneity of AFP content within an AFP-positive tumor, such that it is possible to isolate AFP-producing and nonproducing clones from the same tumor, demonstrating the reversibility of this trait (63); and, in moderately differentiated HCC, absence of correlation between cell morphology and AFP-production (5).

Clear and unequivocal interpretation of AFP levels in $\mathrm{HCC}$ requires a knowledge of the precursor cells of HCC, as well as their AFP status. The so-called oval cells, discovered in rat liver at the acute phase of hepatocarcinogen action and AFP production by these cells (64), became the first candidates for liver stem cells or their close progeny, and the most plausible candidates for HCC precursor cells $(65,66)$. Although this hypothesis helped to explain AFP production by HCC, there is no evidence that a significant part of $\mathrm{HCC}$ is derived from the oval cells.

It is possible that the hepatocyte, and not only its precursor, may serve as a progenitor of HCC. Furthermore, the state of the mature hepatocyte is determined by intercellular and cell-matrix interactions and, hence, is dependent on matrix composition and the presence of receptors responsible for such interactions. The developmental regulation of AFP may be based on the appearance of putative receptors associated with the transition from hepatoblast to hepatocyte with simultaneous formation of adequate matrix. Poorly differentiated anaplastic hepatomas may be devoid of receptors, while highly differentiated tumors may have both systems unimpaired, leading to AFP suppression. In moderately differentiated HCC, variations in matrix composition in a particular tumor and in different parts of the same tumor may in part explain the tremendous variation in AFP production. Mutations and epigenetic events may further account for this variation. Clearly, much investigation remains in order to advance the understanding of AFP production on HCC. 
A constant rise in, and persistent level of, AFP is observed in certain malignancies, namely GCT $(15,20)$, pediatric hepatoblastoma $(\mathrm{Hb})$, hepatocellular carcinoma $(\mathrm{HCC})(14,15,17)$, and, in rare cases, tumors of the gastrointestinal tract (14). Interestingly, these tumors correspond exactly to physiological sites of AFP synthesis $(5,9)$. Serum AFP and its dynamics in these malignancies serve to establish the differential diagnosis and assist in evaluation of treatment.

The prenatal diagnosis of fetal malformations, primarily neural tube defects such as anencephaly and spina bifida, has become an important field of AFP application. A significant increase of AFP levels above normal values in maternal sera indicates a high risk for these fetal defects in the first half of pregnancy. By contrast, a decrease of AFP levels in maternal blood is an important indication of Down's syndrome in the fetus. Pregnancy monitoring by AFP tests is not only necessary in high-risk families with a high probability of defects, but has also become a fairly common test in normal pregnancies (20).

An AFP test is routinely used for differential diagnosis, as well as for monitoring of surgery and chemotherapy, in GCT, Hb, and HCC. AFP reappears in the blood of patients exactly when the cells producing this protein arise in the organism. These are the YSVE cells in GCT, hepatoblast-like cells in Hb, and transformed hepatocytes in benign liver diseases and liver metastases. Moreover, the frequency and level of AFP in the circulation is determined by the presence and type of AFP-producing cells. Representative data on AFP in different pathological conditions from among several thousands of published observations have been summarized previously by the first author (15).

The formal threshold level of AFP above which pathology must be suspected is approximately $500 \mathrm{ng} / \mathrm{ml}$. Whereas this level is approached in GCT, $\mathrm{Hb}$, and $\mathrm{HCC}$, it does not apply to liver metastases of non-HCC cancers. The lectin-binding properties of AFP distinguishes these tumors from liver-produced AFP $(24,25)$. Hence, AFP in testicular and ovarian tumors is close to an "absolute marker" for EC and yolk sac tumours (YST), especially when combined with CGT $(15,62)$. EC and YST in children are particularly suitable for serological diagnosis since AFP reappears in $80-90 \%$ of these cases and achieves supranormal levels in approximately $80 \%$ (15). The incidence of AFP serum elevations in adult GCT is similar but AFP levels are significantly lower, with less than $50 \%$ of cases over $1000 \mathrm{ng} / \mathrm{ml}$. Pediatric $\mathrm{Hb}$ is seropositive for AFP in almost $100 \%$ of cases, with AFP levels higher than $1000 \mathrm{ng} / \mathrm{ml}$ in over $80 \%$ of cases.

AFP in GCT provides a very high, if not absolute, specificity to differentiate EC and YST from seminoma, dysgerminoma, and stromal cell tumors. Its short half-life, approximately five days, allows for its routine use in the evaluation of the effects of surgery or chemotherapy soon after treatment. Reappearance of AFP, in the case of GCT, is a very safe and valuable indicator of clinically inapparent residual tumor, relapse, or distant metastases, and can serve as sufficient grounds for the second-look operation or resumption of chemotherapy $(15,18)$.

The role of AFP in detection and treatment monitoring of $\mathrm{HCC}$ is more complicated. The maximal rate of HCC detection with supranormal AFP is less than $70 \%$, with some variation with age and geographical distribution. Levels of AFP found in 10-15\% of HCC cases are below the specificity threshold of the serum assay, as is the case for benign liver disease and liver metastases. For differentiating these tumor types, dynamics studies of AFP level are essential. In this regard, a stable or rising AFP has been shown to be typical of HCC, an undulating pattern is characteristic of cirrhosis, and a wave-like pattern is suggestive of viral hepatitis (67).

Analyses of subfraction composition of AFP in patient sera, characterized according to lectin-reactivity $(24,25,68)$, has also shown promise in distinguishing these tumor types. More research in this area is necessary in order to achieve early detection and diagnosis of HCC, while still in the operable state. 
The establishment of high-risk groups and the possibility of serially screening individuals in these groups have raised interesting prospects. The identification of high risk groups has not been possible up to now for GCT, but it has been achieved in HCC for populations in South and West Africa and in South-East Asia. Screening for AFP was moderately successful in detecting clinically unsuspected liver cancer in West Africa (69), and was highly successful in China. Among 3.4 million Chinese individuals tested, 782 AFP-positive cases were revealed, among them 301 clinically asymptomatic cases (70). In addition, studies of patients with liver cirrhosis have supported the utility of AFP measurements (71). Most promising of all were seroepidemiological investigations of Alaskan Native chronic carriers of HBs-antigen, among whom $30 \%$ of AFP-positive persons proved to have operable HCC (72). At present, chronic HBs Ag carriers in regions of the world with high consumption of aflatoxin are likely to constitute the most adequate population for AFP screening.

\section{CONCLUSION}

Despite much advancement in the knowledge of AFP biology and in its clinical applications, many avenues of both basic and clinical research remain. With the diagnostic roles of AFP largely established, future research will emphasize the biology of AFP: its suggested functions, plausible receptors, and transcriptional regulators, and the involvement of these in intercellular communications. In addition, as new knowledge accumulates, novel and unexpected clinical applications of AFP promise to arise.

\section{REFERENCES}

1. Bergstrand CG, Czar B. Demonstration of a new protein fraction in serum from the human fetus. Scandinavian Journal of Clinical Laboratory and Investigations 8: 174-179; 1956.

2. Abelev GI. Alpha-fetoprotein: the genesis. Oncodevelopmental Biology and Medicine 4: 371-381; 1983.

3. Abelev GI, Perova S, Khramkova NI, et al. Production of embryonal alpha-globulin by the transplantable mouse hepatomas. Transplantation 1: 174-180; 1963.

4. Tatarinov YS. Presence of embryonal alpha-globulin in the serum of patient with primary hepatocellular carcinoma. Voprosy Medicinskoy Chimii 10: 90-91; 1964.

5. Abelev GI. Alpha-fetoprotein in ontogenesis and its association with malignant tumors. Advances in Cancer Research 14: 295-358; 1971.

6. Abelev GI. The origin of the cancer immunodiagnosis. In: Mazumdar PMH, ed. Immunology 1930-1980. Essays on the History of Immunology. Toronto: Wall \& Tompson; 1989: 275-290.

7. Abelev GI, Assecritova IV, Kraevsky NA, et al. Embryonal serum alpha-globulin in cancer patients: diagnostic value. International Journal of Cancer 2: 551-558; 1967.

8. Masopust J, Kithier R, Radl I, et al. Occurrence of fetoprotein in patients with neoplasms and nonneoplastic disease. International Journal of Cancer 3:364-370; 1968.

9. Abelev GI. Alpha-Fetoprotein as a marker of embryo-specific differentiations in normal and tumor tissues. Transplantation Reviews 20: 3-37; 1974.

10. Ruoslahti E, Seppala M. Studies of carcino-fetal proteins. III. Development of radio-immunoassay for alpha-fetoprotein. Demonstration of alpha-fetoprotein in serum of healthy human adults. International Journal of Cancer 8: 374-383, 1971. 
11. Brock D, Sutcliffe R. Alpha-fetoprotein in antenatal diagnosis of anencephaly and spina bifida. Lancet ii:197; 1972.

12. Milunsky A, Alper E,. Results and benefits of a maternal serum alpha-fetoprotein screening program. Journal of American Medical Association 252: 1438-1442; 1984.

13. Norgaard-Pedersen B, Larsen SO, Anders J, et al. Maternal serum markers in screening for Down syndrome. Clinical Genetics 36: 1-9; 1989.

14. Masseyeff R. Human alpha-feto-protein (Review). Pathologie Biologie 20: 703-727; 1972.

15. Abelev GI, Elgort DA. Alpha-fetoprotein. In: Holland J, Frei E, eds. Cancer Medicine, 2nd edition. New York: Lea \& Febiger 1982: 1089-1099.

16. Abelev GI. Alpha-fetoprotein: 25 years of study. Tumor Biology 10: 63-74; 1989.

17. Abelev GI. Antigenic structure of chemically-induced hepatomas. Progress in Experimental Tumor Research 7: 104-157; 1965.

18. Deutsch HF. Chemistry and biology of alpha-fetoprotein. Advances in Cancer Research 56: 253-312; 1991.

19. Mizejewski GI. The filogeny of alpha-fetoprotein in vertebrates: survey of biochemical and physiological data. Critical Reviews in Eucariotic Gene Expression 5: 281-316; 1995.

20. Ruoslahti E, Seppala M. Alpha-Fetoprotein in cancer and fetal development. Advances in Cancer Research 29: 275-346; 1979.

21. Christiansen M, Yazova AK, Karamova ER, et al. Epitopes of human alpha-fetoprotein. Journal of Tumor Marker Oncology 9: 57-68; 1994.

22. Kitatawa H, Ohkouchi E, Jan-Ichi H, et al. Monoclonal antibodies with fine specifities distinguishing alphafetoprotein of hepatoma and yolk sac tumor origin. International Japanese Cancer Research 77: 1012$1017 ; 1986$.

23. Smith C, Kelleher P. Alpha-fetoprotein molecular heterogeneity. Physiologic correlation with normal growth, carcinogenesis and tumor growth. Biochemica and Biophysica Acta 605: 1-32; 1980.

24. Breborowich J. Microheterogeneity of human alphafetoprotein. Tumor Biology 9: 3-14; 1988.

25. Taketa K. Alpha-Fetoprotein: reevaluation in hepatology. Hepatology 12: 1420-1432; 1990.

26. Yazova AK, Yakimenko EF, Goussev AI, et al. Differences in epitope structure of human AFP revealed by monoclonal antibodies. Abstracts of XXIV ISOBM Meeting, San-Diego, 1996 (In press).

27. Parmelee M, Evenson M, Deutsch $\mathrm{H}$. The presence of fatty acids in human alpha-fetoprotein. Journal of Biological Chemistry 253: 2114-2119; 1978.

28. Uriel J, Laborda J, Naval J, et al. AFP receptors in malignant cells (an overview). In: Mizejewski GI, Jacobson HI, eds. Biological Activities of Alpha1-Fetoprotein, vol 2. Boca Raton, Florida: CRC Press; 1989: 103-118. 
29. Hsia JC, Wong LT, Trimble CE, et al. In: Mizejewski GI, Jacobson HI, eds. Biological Activities of Alpha1-Fetoprotein, vol 1. Boca Raton, Florida: CRC Press; 1987: 189-204.

30. Moro R. The AFP receptor - a widespread oncofetal antigen. In: Mizeyewski GI, Jacobson HI, eds. Biological Activities of Alpha1-Fetoprotein, vol 2. Boca Raton, Florida: CRC Press; 1989: 119-128.

31. Deutsch H. The uptake of adriamycyn-arachidonic acid complexes by human tumor cells in the presence of

alpha-fetoprotein. Journal of Tumor Marker Oncology 9: 11-14; 1994.

32. Nunez EA, Engelman F, Benassayag C, et al. Identification et purification preliminaire de la foetoproteine liant les oestrogenes dan le serumde rats nourveau-nes. Comptes Rendue de'l Academie de Sciences (Paris) 273: 831-834; 1971.

33. Nunez EA, Benassayag $\mathrm{C}$, Christeff $\mathrm{N}$, et al. Estrogen and fatty acid binding properties of murine AFP: a guide to explain some biological activities of this protein. In: Mizeyewski GI, Jacobson HI, eds. Biological Activities of Alpha1-Fetoprotein, vol 2. Boca Raton, Florida: CRC Press; 1989: 3-18.

34. Mizeyewski GI, Stanton BR, Jacobson HI. AFP modification of biological response in estrogen-sensitive tissues. Use of in vivo and in vitro models. In: Mizeyewski GI, Jacobson HI, eds. Biological Activities of Alpha1-Fetoprotein, vol 2. Boca Raton, Florida: CRC Press; 1989: 59-74.

35. Mizejewski GI, Jacobson HI, eds. Biological Activities of Alpha1-Fetoprotein. Boca Raton, Florida: CRC Press; vol 1, 1987; vol 2, 1989.

36. Lester EP, Miller JB, Baron JM, et al. Inhibition of human lymphocyte transformation by human alphafetoprotein (HAFP): studies on the mode of HAFP action and the role of HAFP polymorphism. Immunology 34: 189-194; 1976.

37. Lu CY, Changelian PS, Unanue ER. Alpha-fetoprotein inhibits macrophage expression of Ia antigen. Journal of Immunology 132: 1722-1727; 1984.

38. Gitlin D, Boesman M. Sites of serum alpha-fetoprotein synthesis in the human and rat. Journal of Clinical Investigations 46: 1010-1016; 1967.

39. Gitlin D, Pericelli A, Gitlin C. Synthesis of alpha-fetoprotein by liver, yolk sac and gastrointestinal tract of the human concepts. Cancer Research 32: 979-987; 1972.

40. Dziadek M. Modulation of alpha-fetoprotein synthesis in the early post-implantation embryo. Journal of Embryology and Experimental Morphology 46: 135-146; 1978.

41. Gleiberman AS, Abelev GI. Cell position and cell interactions in expression of fetal phenotype of hepatocyte. International Review of Cytology 95: 229-266; 1985.

42. Abelev GI. Study of the regulation of alpha-fetoprotein synthesis in ontogenesis and carcinogenesis. In: Skulachev VP, ed. Soviet Science Review (section D) Biological Reviews. New York: Harwood Acad Publ.: 1: 371-397; 1980.

43. Baranov VN, Engelhardt NV. Immunoperoxidase technique in electron microscopy: theoretical and practical aspects and use of localization of alpha-fetoprotein synthesis. In: Blokhin NN, Trapeznikov NN, eds. Soviet Medical Reviews (Section F) Oncology. New York: Harwood Acad Publ; 1: 119-163; 1987. 
44. Gleiberman AS, Kudryavtseva EI, Sharovskaya YY, et al. The synthesis of alpha-fetoprotein in hepatocytes is coordinately regulated with cell-cell and cell-matrix interactions. Molecular Biology and Medicine 6: 95-107; 1989.

45. Harper ME, Dugaiczyk A. Linkage of the evolutionary related serum albumin and alpha-fetoprotein genes within q11-22 of human chromosome 4. American Journal of Human Genetics 35: 565-572; 1983.

46. Belanger L, Sylvie R, Allard D. New albumin gene 3' adjacent to the alpha-fetoprotein locus. Journal of Biological Chemistry 269: 5481-5484; 1994.

47. Gibbs PEM, Zielinski R, Boyd C, et al. Structure, polymorphism, and novel repeat DNA elements revealed by a complete sequence of the human alpha-fetoprotein gene. Biochemistry 26: 1332-1341; 1987.

48. Godbout R, Ingram R, Tilghman SM. Fine-structure mapping of the three mouse alpha-fetoprotein gene enhancers. Molecular and Cellular Biology 8: 1169-1178; 1988.

49. Guertin M, La Rue H, Bernier D, et al. Enhancer and promoter elements directing activation and glucocorticoid repression of the alpha-fetoprotein gene in hepatocytes. Molecular and Cellular Biology 8: 1398-1407; 1988.

50. Wen P, Group ER, Bruzard G, et al. Enhancer, repressor and promoter specificities combine to regulate the rat alpha-fetoprotein gene. DNA and Cell Biology 10: 525-536; 1991.

51. Vacher J, Tilghman SM. Dominant negative regulation of the mouse alpha-fetoprotein gene in adult liver. Science 250: 1732-1735; 1990.

52. Ramesh TM, Ellis AW, Spear BT. Individual mouse alpha-fetoprotein enhancer elements exhibit different patterns of tissue-specific and hepatic position-dependent activities. Molecular and Cellular Biology 15: $4947-4955 ; 1995$.

53. Bernier D, Thomassin H, Allard D, et al. Functional analysis of developmentally regulated chromatinhypersensitive domains carrying the alpha-fetoprotein intergenic enhancer. Molecular and Cellular Biology 13: 1619-1633; 1993.

54. Wen P, Locker J. A novel hepatocyte transcription factor that binds the alpha-fetoprotein promoter-linked coupling element. Molecular and Cellular Biology 14: 6616-6626; 1994.

55. Tronche F, Yaniv M. HNF-1, a homeoprotein member of the hepatic transcription regulatory network. BioEssays, 14: 579-587; 1992.

56. Belayew A, Tilghman SM. Genetic analysis of alpha-fetoprotein synthesis in the mouse. Molecular and Cellular Biology 2: 1427-1435; 1982.

57. Vacher J, Camper SA, Krumlauf R, et al. raf regulates the postnatal repression of the mouse alphafetoprotein gene at the posttranscriptional level. Molecular and Cellular Biology 12: 856-864; 1992.

58. Spear BT. Mouse alpha-fetoprotein gene 5 ' regulatory elements are required for postnatal regulation by raf and Rif. Molecular and Cellular Biology 14: 6497- 6505; 1994.

59. Yasuda H, Mizuno A, Tamaoki T, et al. ATBF1, a multiple-homeodomain zinc finger protein, selectively down-regulates AT-rich elements of the human alpha-fetoprotein gene. Molecular and Cellular Biology 14: 1395-1401; 1994. 
60. Engelhardt NV, Poltoranina VS, Yazova AK. Localization of alpha-fetoprotein in transplantable murine teratocarcinomas. International Journal of Cancer 11;448-459; 1973.

61. Teilum G. Special tumors of ovary and testis, II edition. Copenhagen: Munsgaard; 1976.

62. Lightner DJ, Longe P. Testicular tumors. In: Herberman RB, Mercer DW, eds. Immunodiagnosis of Cancer, II edition. New York: Marcel Dekker; 1990: 397-401.

63. Eraizer TL, Khamzina LS. Phenotypic variability of cultured rat hepatoma cell population in respect to alpha-fetoprotein synthesis. International Journal of Cancer 42: 633-637; 1988.

64. Kutagawa T, Yokochi T, Sugano H. Alpha-Fetoprotein and hepatocarcinogenesis in rats fed 3'-methyl-4(dimethylamino)azobenzene and N-2-fluorenyl-acetate. International Journal of Cancer 10: 368-381; 1972.

65. Sell S. Is there a liver stem cell? Cancer Research 50: 3811-3815; 1990.

66. Sell S, Hunt J, Knoll B, et al. Cellular events during hepatocarcinogenesis in rats and the question of premalignancy. Advances in Cancer Research 48: 37-111; 1987.

67. Wu AHB, Sell S. Markers of hepatocellular carcinoma. In: Herberman RB, Mercer DW, eds. Immunodiagnosis of Cancer, II edition. New York: Marcel Dekker; 1990: 403-422.

68. Burditte LJ, Johnson MM, Johnson PI, et al. Detection of hepatocellular carcinoma-specific alphafetoprotein by isoelectric focusing. Cancer 74, 25-29; 1994.

69. Masseyeff R. Alpha-fetoprotein -- use in screening. In: Herberman RB, McIntire KR, eds. Immunodiagnosis of Cancer, I edition. New York: Marcel Dekker; 1979: 117-130.

70. Xu K-L. Large screening for hepatocellular carcinoma in China. In: Fishman WH, ed. Oncodevelopmental Markers. New York: Academic Press; 1983: 395-408.

71. Lehmann F-G. Prognostic significance of alpha-1-fetoprotein in liver cirrhosis. Five-years perspective study. In: Fishman WH, Sell S, eds. Oncodevelopmental Gene Expression. New York: Academic Press; 1976: 407-416.

72. McMahon B, London T. Workshop on screening on hepatocellular carcinoma. Journal of National Cancer Institute 83: 916-920; 1991.

73. Abelev GI. Alpha-fetoprotein biology. In: Skulachev VP, ed. Soviet Science Review (section D) Physicochemical Biology. New York: Harwood Acad Publ; 11: 85-109; 1993.

74. Christiansen M, Ishiguro T, Hogdall C, et al. Alpha-fetoprotein. In: Ballesta AM, Torre G, Bombardieri E, et al, eds. Up Dating of Tumor Markers in Tissues and in Biological Fluids. Torino: Edizoni Minerva Medica; 1993: 245-269.

\section{BIOGRAPHY}

Garry I. Abelev, Ph.D., Dr. Sci., is the discoverer of alpha-fetoprotein (AFP) as a human tumor marker. He has been a corresponding member of the Russian Academy of Sciences since 1987, and is Head of the Immunochemistry Laboratory, Cancer Research Center (Moscow, Russia) and Professor at Moscow State 
University. Natalia L. Lazarevich is Head of the Molecular Biology team of the Immunochemistry Laboratory, Cancer Research Center. She graduated with a degree in Virology from Moscow State University in 1989, and devoted her Ph.D. dissertation to the molecular aspects of AFP regulation.

Copyright (C) 1996 by MJM 